\title{
Dexamethasone therapy and rates of secondary pulmonary and bloodstream infections in critically ill COVID-19 patients
}

\author{
Kathrin Rothe, ${ }^{1}$ Tobias Lahmer, ${ }^{2}$ Sebastian Rasch, ${ }^{2}$ Jochen Schneider, ${ }^{2}$ Christoph D. Spinner, ${ }^{2,3}$ Fabian Wallnöfer, ${ }^{2}$ \\ Milena Wurst, ${ }^{2}$ Roland M. Schmid, ${ }^{2}$ Birgit Waschulzik, ${ }^{4}$ Kristina Fuest, ${ }^{5}$ Silja Kriescher, ${ }^{5}$ Gerhard Schneider, \\ Dirk H. Busch, ${ }^{1,3}$ Susanne Feihl, ${ }^{1}$ Markus Heim ${ }^{5}$ \\ ${ }^{1}$ Institute for Medical Microbiology, Immunology and Hygiene, Technical University of Munich, School of Medicine, \\ Munich; ${ }^{2}$ Department of Internal Medicine II, Technical University of Munich, School of Medicine, Munich; ${ }^{3}$ German \\ Center for Infection Research (DZIF), Partner Site Munich, Munich; ${ }^{4}$ Institute of Medical Informatics, Statistics and \\ Epidemiology, Technical University of Munich, School of Medicine, Munich; ${ }^{5}$ Department of Anaesthesiology and Intensive \\ Care Medicine, Technical University of Munich, School of Medicine, Munich, Germany
}

Background: Coronavirus disease 2019 (COVID-19) has become a pandemic. Bacterial superinfections seem to be associated with higher mortality in COVID-19 patients in intensive care units (ICUs). However, details on the prevalence and species distribution of secondary infections are limited. Moreover, the increasing use of dexamethasone may pose an additional risk of superinfections.

Methods: We performed a single-center retrospective study of the clinical and microbiological characteristics of 154 COVID-19 patients admitted to the ICU between March 2020 and January 2021, focusing on bacterial infections, use of antimicrobial agents and dexamethasone therapy.

Results: The median age was 68 years; $67.5 \%$ of the patients were men. Critically ill COVID-19 patients were treated with dexamethasone since July 2020 (second wave), which was not common during the first wave of the pandemic. In the dexamethasone group $(n=90,58.4 \%)$, respiratory pathogens were detected more frequently, as were multidrugresistant pathogens. The number of patients with polymicrobial detection of respiratory pathogens was significantly increased $(\mathrm{p}=0.013)$. The most frequently detected species were Enterobacterales, Staphylococcus aureus, and Aspergillus fumigatus. The rates of bloodstream infections did not differ between the groups. The use of dexamethasone in ICU COVID-19 patients was associated with higher rates of respiratory infectious complications.

Conclusions: Secondary infections are present in a substantial fraction of critically ill COVID-19 patients. Respiratory pathogens were detectable in the majority of COVID-19 ICU patients. The use of dexamethasone poses a potential risk of secondary pulmonary infections. Infectious complications in patients with dexamethasone therapy could be associated with worse outcomes.

Key words: COVID-19; SARS-CoV-2; critical care; antibiotic stewardship; bacterial infection; dexamethasone.

Correspondence: Dr. Markus Heim, Department of Anaesthesiology and Intensive Care Medicine, Technical University of Munich, School of Medicine, University Hospital rechts der Isar, Ismaninger Str. 22, 81675 Munich, Germany.

Tel.+49.89.41405990 - Fax: +49.89.41404804. E-mail: m.heim@tum.de

Contributions: KR, MH, conceptualization, investigation, project administration: FW, MW, SK, KR, MH, data curation; KR, $\mathrm{MH}$, formal analysis; BW, statistical analysis; KR, MH, writing original draft; TL, SR, JS, CDS, RMS, KF, SK, GS, DHB, SF, supervision, review, and editing. All authors have read and approved the final version of the manuscript and agreed to be accountable for all aspects of the work.

Conflict of interest: Susanne Feihl reports personal fees and non-financial support from Smith and Nephew, personal fees and non-financial support from Curetis, personal fees and non-financial support from Zimmer Biomet, personal fees and non-financial support from Limbach, personal fees and non-financial support from MSD, outside the submitted work. Sebastian Rasch reports travel-grants from Gilead, outside the submitted work. Christoph D. Spinner reports grants, personal fees, and nonfinancial support from Gilead Sciences, grants and personal fees from Janssen-Cilag, personal fees from Formycon, other from Apeiron, other from Eli Lilly, during the conduct of the study; personal fees from AbbVie, personal fees from MSD, grants and personal fees from GSK/ViiV Healthcare, outside the submitted work. All other authors have no conflicts of interest to disclose.

Funding: This research did not receive any specific grant from funding agencies in the public, commercial, or not-for-profit sectors.

Ethics approval and consent to participate: The Ethics Committee of the Technical University of Munich approved the protocol of this retrospective study and waived the need to obtain consent for the collection, analysis and publication of the data (approval no. 78/21 S).

Availability of data and material: All relevant data are made available in the manuscript and supplementary files. 


\section{Introduction}

The coronavirus disease 2019 (COVID-19) caused by severe acute respiratory syndrome coronavirus 2 (SARS-CoV-2) is characterized by often mild or uncomplicated respiratory illness. Complications such as secondary infections, acute respiratory distress syndrome (ARDS), sepsis, and multi-organ failure can occur in a substantial proportion of critically ill hospitalized patients $[1,2]$. Confirmed community-onset bacterial co-infection was detected in only $3-5 \%$ of all COVID-19 cases, but more than $50 \%$ of these patients were treated with an empirical antibiotic therapy [3]. In a recent meta-analysis, only 7\% of the hospitalized COVID19 patients developed secondary bacterial infections during the course of the disease and for patients in intensive care units (ICUs), the infection rate increased to $14 \%$ [4]. Zhou et al. reported the occurrence of secondary infections in $50 \%$ of all non-survivors and reasoned that COVID-19 patients were more likely to die when suffering from secondary infections [5]. However, the widespread use of empirical antibiotics contrasts with the low rate of detected superinfections [6]. The overuse of antimicrobial agents increases the risk of multidrug-resistant nosocomial secondary infections, which are associated with unfavorable clinical outcomes [7]. Therefore, the practice of antibiotic coverage in COVID-19 patients must be carefully evaluated. Contrarily, antibiotic overuse would lead to low rates of detection and reporting of secondary infections, resulting in underestimation of the prevalence of bacterial infections during the pandemic [8]. Elevated inflammatory markers, clinical presentation, and bilateral radiological infiltrates could lead to misinterpretations regarding the presence of secondary bacterial infections in the clinical management of COVID-19 patients.

As a consequence of the preliminary report of the RECOVERY trial and the WHO REACT meta-analysis, clinicians worldwide increased the use of dexamethasone as an adjunct treatment in critically ill COVID-19 patients $[9,10]$. This approach was additionally supported by data from the DEXA ARDS trial published in 2020 and represents a paradigm shift, as previously the use of glucocorticoids was not recommended or even stated as contraindicated in many treatment guidelines for COVID-19 [11,12]. In addition to the common adverse effects e.g. metabolic complications or gastrointestinal bleeding, glucocorticoids were suspected to increase secondary infections [13], especially since lower viral clearance has been reported in influenza, MERS and SARS patients on glucocorticoid therapy [14-16]. While dexamethasone was not routinely used in critically ill patients in the first wave of the COVID-19 pandemic, this therapy was part of standard care since July 2020 at our institution. Therefore, the aim of our study was to evaluate COVID-19 patients requiring ICU treatment with or without dexamethasone therapy regarding possible differences in detection of secondary infections with focus on pulmonary and bloodstream infections representing the most frequent infectious complications of COVID-19 patients requiring ICU treatment. Also, the used antibiotic strategies and clinical parameters of patients in the first wave (without dexamethasone) were compared to patients in the second wave of the pandemic (with dexamethasone) to elucidate potential differences in epidemiology and antibiotic management between the two groups at different time points in the pandemic.

\section{Methods}

The Ethics Committee of the Technical University of Munich approved the protocol of this retrospective study and waived the need to obtain consent for the collection, analysis and publication of the data (approval no. 78/21 S). The study protocol was per- formed in accordance with the relevant guidelines.

We performed a retrospective, single-center, cohort study of 154 adult patients with laboratory-confirmed acute primary COVID-19 admitted to the ICU between March 11, 2020, and January 03,2021 . According to our standard operating procedure for COVID-19 patients, the need for intensive care was discussed when the respiratory rate rose above 30 per minute and $\mathrm{SpO}_{2}$ fell below $90 \%$ at an oxygen flow rate of $8 \mathrm{~L} / \mathrm{min}$ by face mask. Patients were treated in two different ICUs in a university hospital with 1,163 beds, one affiliated with the Department of Internal Medicine and the other to the Department of Anaesthesiology and Intensive Care Medicine.

Medical records, including clinical charts and nursing records, were reviewed and the data were extracted after review. The data collected included patient biometrics, comorbidities, clinical parameters, laboratory findings, information on in-patient management, ICU interventions, as well as ICU and hospital stays. SARSCoV-2 was confirmed by RT-PCR of respiratory swabs or a combination of $\mathrm{IgG} / \mathrm{IgM}$ seropositivity and COVID-19 symptoms. Details of data extraction and testing methods are published elsewhere [17]. Patients with positive RT-PCR results were defined as those with definite COVID-19, and those who could not be confirmed were excluded from the analysis. Patients with and without dexamethasone therapy were compared regarding the rate of infectious complications, clinical parameters and antibiotic strategies. Dexamethasone was not routinely used in critically ill patients in the first wave of the COVID-19 pandemic, but was part of standard care since July 2020. Dexamethasone therapy was not deliberately selected for specific patients but was used in accordance with current treatment standards for patients with a room air saturation below $90 \%$ or those with oxygen demand as well as patients who had to be treated at the ICU. Patients in the dexamethasone group received $6 \mathrm{mg}$ of dexamethasone i.v. per day for a total of 10 days.

Microbiological analysis of secondary infections was focused on respiratory infections and bloodstream infections only. Urine samples were used for lateral flow antigen test to detect Legionella pneumophila serogroup 1 and Streptococcus pneumoniae (BinaxNOW ${ }^{\circledR}$, Abbott, Chicago, IL, USA). For blood culture (BC) diagnostics, blood was inoculated in aerobic and anaerobic media (BACTEC ${ }^{\text {тм }}$ Plus, Becton Dickinson, Sparks, MD, USA) for processing via an automated BC system. Culture bottles were incubated for 5-7 days, according to the manufacturer's recommendations. BCs were only obtained in case of clinical signs of (bloodstream) infection, such as rising inflammatory laboratory parameters (leucocyte count, CPR, PCT) and elevated temperature but not as part of the longitudinal sampling strategy. Considering the difficulty in determining the clinical significance of coagulase-negative staphylococci (CoNS) in BC, these isolates were reviewed separately and considered clinically significant if two or more bottles yielded the same CoNS. In our longitudinal sampling approach, tracheal secretion or bronchoalveolar lavage fluid (BAL) of ICU COVID-19 patients was gained at ICU admission and then at clinical signs of respiratory infection as defined by the physician in charge or at least once weekly during ICU stay. Primary microbiological cultures of respiratory samples were performed on Columbia agar, Schaedler agar, and chocolate agar (prepared culture media, Becton Dickinson, Sparks, MD, USA). Quantitative cultures of BAL fluids were not performed due to safety reasons for laboratory personnel. Species identification (matrix-assisted laser desorption ionization time-of-flight mass spectrometry (MALI-TOF MS), Bruker Daltronics, Leipzig, Germany) and automated antimicrobial susceptibility testing $\left(\mathrm{VITEK}^{\circledR}\right.$, bioMerieux, Marcy l'Etoile, France) were performed for all relevant pathogens. Advanced analysis in cases of suspected multiresistance was performed via lateral flow assay for detection of carbapenemases (Coris BioConcept, Belgium) and via PCR for 
suspected vancomycin-resistant Enterococci (GeneXpert, Cepheid, CA, USA). For data analysis, separate pathogen species were included once per patient, regardless of the number of detections in consecutive longitudinal sampling of respiratory specimens. Detection of organisms without relevant pathogenicity for ventilator-associated pneumonia in BAL-fluid or tracheal secretion, such as Enterococcus spp., Candida spp., CoNS, and Viridans streptococci [18], were not reported as detected respiratory pathogens. GM detection (PlateliaTM Aspergillus Ag, Bio-Rad Laboratories, Munich, Germany) was performed in BAL-fluid or tracheal secretion parallel to fungal culture. Results were reported as optical density index (ODI) with a cut-off of 0.5 .

\section{Statistical analysis}

Continuous data were described by median, $25^{\text {th }}$ and $75^{\text {th }}$ percentiles, and categorical data by absolute and relative frequencies. Relevant characteristics of the groups treated with or without dexamethasone were compared by Mann-Whitney U test (continuous variables) and chi-squared test or Fisher's exact test (categorical variables), respectively. Survival times for overall survival in the hospital were analyzed using Kaplan-Meier curves and compared by Log rank test. Survival analysis was performed by Cox regression with dexamethasone and age as independent variables. Logistic regression models were fitted to the data for binary outcomes (detection of respiratory pathogens, polymicrobial detection of respiratory pathogens and detection of $A$. fumigatus as well as blood stream infections) with dexamethasone, number of comorbidities and sex as covariates. Higher age and pre-existing comorbidities were selected as previously described risk factors for severe outcome in COVID-19 [19,20]. All analyses were conducted two-sided using a 5\% level of significance and $95 \%$ confidence intervals (CI) were calculated for relevant effect sizes. Statistical analyses were performed using Microsoft Excel 2013 and IBM SPSS Statistics v. 25.0 (IBM Corp, Armonk, NY, USA).

\section{Results}

A total of 154 ICU COVID-19 patients were included in the analysis. The median age was 68 years $\left(\mathrm{Q}_{25}-\mathrm{Q}_{75}: 59-78\right)$ and $67.5 \%$ of the patients were males. Dexamethasone was administered to 90 patients $(58.4 \%)$. Patients in the dexamethasone group were significantly older, had a longer ICU stay and more days on a ventilator. Overall, the in-hospital mortality rate was $39.6 \%$ with a higher mortality rate in the dexamethasone group (32.8\% vs. $44.4 \%)$. For the entire cohort, patients on invasive ventilation showed a higher mortality rate $(49.6 \%)$, especially patients on mechanical ventilation and renal replacement therapy simultaneously (65.2\%). Again, patients in the dexamethasone group had an even higher mortality rate than the group without dexamethasone $(55.9 \%$ vs. $40.8 \%$ for mechanical ventilation, and $76.0 \%$ vs. $52.4 \%$ for mechanical ventilation and renal replacement therapy). For details on patient characteristics, see Table 1.

The detected slightly higher in-hospital mortality rate in the dexamethasone group (Figure 1) was not statistically significant (unadjusted HR: 1.64, 95\% CI 0.96 - 2.78), however, after adjustment for age and sex via Cox regression we could still detect an association of dexamethasone therapy with increased mortality in our cohort (HR adjusted for age and sex: 1.48, 95\% CI 0.87 - 2.53).

As expected, non-survivors were older, had a longer hospital stay, and were in poorer condition upon ICU admission, with significantly higher procalcitonin (PCT), IL-6, and D-dimer levels, and higher Sequential Organ Failure Assessment (SOFA) and Acute Physiology, Age and Chronic Health Evaluation (APACHE) scores (all significant). Notably, more of them required proning due to respiratory failure, a greater fraction of them had bloodstream infections (BSIs) and respiratory infections during the ICU stay (Supplementary Table 1).

A majority $(84.9 \%)$ of ICU COVID-19 patients received empirical antibiotic therapy. Immediate empirical antibiotic therapy within 24 hours of hospital admission was more frequently administered during the first wave of the pandemic (patients without dexamethasone therapy). In contrast, in the dexamethasone group (patients of the $2^{\text {nd }}$ wave), with growing awareness of antibiotic stewardship (ABS) principles during the pandemic and knowledge of low rates of initial bacterial secondary infections, significantly fewer patients were administered initial empirical antimicrobial therapy $(77.5 \%$ vs $95.2 \%)$. In line with this principle, empirical administration of azithromycin was significantly rarer in the dexamethasone group. Overall, piperacillin/tazobactam was the most frequently administered empiric antibiotic. However, ampicillin/sulbactam as the primary antibiotic, was significantly less common in the dexamethasone group (patients of the $2^{\text {nd }}$ wave), as patients in this group received antibiotic therapy at a later stage during their hospital stay and then at an advanced disease stage, based on microbiological susceptibility testing. Meropenem was frequently administered as escalation therapy (48.7\%) either as empiric choice or in line with results of susceptibility testing. Underlying microbiological susceptibility testing results indicating requirement for carbapenem therapy were significantly more frequent in the dexamethasone group (Table 1).

BSIs were detected in $29.7 \%$ of ICU COVID-19 patients during their hospital stay. Some patients also suffered from polymicrobial BSI, and the most frequently detected species were Enterobacterales, CoNS, and E. faecium. During the first wave of the pandemic (patients without dexamethasone therapy), more BSIs with CoNS and C. albicans were detected, while $S$. aureus, E. faecalis, and Enterobacterales were more frequent in the dexamethasone group.

Microbiological workup of respiratory specimens directly on admission was only initiated in a small fraction of patients and revealed mainly Enterobacterales and S. aureus. In our longitudinal sampling approach, tracheal secretion or BAL fluid of ICU COVID-19 patients was collected at ICU admission and then once weekly during their ICU stay to detect any relevant pathogens causing potential secondary pulmonary infections. This microbiological diagnostic test revealed respiratory pathogens in $75.0 \%$ of all samples, in $45.4 \%$ polymicrobial detection of respiratory

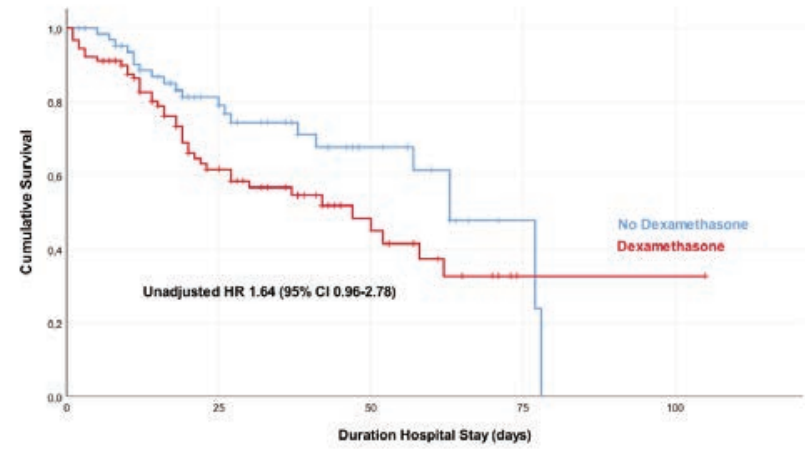

Figure 1. Kaplan-Meier curves for critically ill COVID-19 patients with and without dexamethasone therapy. Curves were compared by log-rank test. Survival analysis was performed by Cox regression with dexamethasone, sex and age as independent variables and showed an association of dexamethasone therapy with increased mortality (unadjusted HR 1.64, 95\% CI 0.96 2.78; adjusted for age and sex HR 1.48, 95\% CI 0,87 - 2.53). 
Table 1. Relevant characteristics of the study cohort of critically-ill COVID-19 patients with and without dexamethasone therapy.

\begin{tabular}{|c|c|c|c|c|}
\hline $\begin{array}{l}\text { Characteristics* [Median }\left(25^{\text {th }} \text { and } 75^{\text {th }} \text { percentiles }\right) \\
\text { unless otherwise indicated] }\end{array}$ & Total cohort & $\begin{array}{c}\text { No } \\
\text { dexamethasone }\end{array}$ & $\begin{array}{l}\text { Dexamethasone } \\
\text { group }\end{array}$ & $\mathbf{p}^{\#}$ \\
\hline Age (years), $n=154$ & $68(59-78)$ & $65(53-77)$ & $70(65-78)$ & 0.031 \\
\hline Male sex, $\mathrm{n} / \mathrm{N}(\%)$ & $104 / 154(67.5)$ & $44 / 64(68.8)$ & $60 / 90(66.7)$ & 0.786 \\
\hline $\mathrm{BMI}^{\circ}, \mathrm{n}=150$ & $26.23(23.67-29.86)$ & $25.59(23.15-31.74)$ & $26.63(23.91-29.39)$ & 0.694 \\
\hline Mortality in ICU, n/N (\%) & $60 / 154(39.0)$ & 20/64 (31.3) & $40 / 90(44.4)$ & 0.098 \\
\hline Mortality in hospital, n/N (\%) & $61 / 154(39.6)$ & 21/64 (32.8) & $40 / 90(44.4)$ & 0.146 \\
\hline Duration of ICU stay (days), $\mathrm{n}=154$ & $13(5-27)$ & $12(6-33)$ & $13(4-23)$ & 0.374 \\
\hline Duration of hospital stay (days), $\mathrm{n}=154$ & $24(14-42)$ & $27(16-45)$ & $21(12-39)$ & 0.128 \\
\hline $\begin{array}{l}\text { Comorbidities } \\
\text { Number of comorbidities, } \mathrm{n}=154 \\
\text { No comorbidity present, } \mathrm{n} / \mathrm{N}(\%) \\
\text { Obesity }\left(\mathrm{BMI} \mathrm{c}^{\mathrm{a}} \geq 30\right), \mathrm{n} / \mathrm{N}(\%) \\
\text { Arterial hypertension, } \mathrm{n} / \mathrm{N}(\%) \\
\text { Diabetes mellitus, } \mathrm{n} / \mathrm{N}(\%) \\
\text { Coronary heart disease, } \mathrm{n} / \mathrm{N}(\%) \\
\text { Chronic or end-stage kidney disease, } \mathrm{n} / \mathrm{N}(\%) \\
\text { Cancer, } \mathrm{n} / \mathrm{N}(\%) \\
\text { Immunosuppression, } \mathrm{n} / \mathrm{N}(\%) \\
\text { COPD, } \mathrm{n} / \mathrm{N}(\%) \\
\text { Bronchial asthma, } \mathrm{n} / \mathrm{N}(\%) \\
\text { Other }{ }^{\S}, \mathrm{n} / \mathrm{N}(\%)\end{array}$ & $\begin{array}{c}2(1-3) \\
23 / 154(14.9) \\
37 / 154(24.7) \\
99 / 154(64.3) \\
55 / 154(35.7) \\
42 / 154(27.3) \\
30 / 154(19.5) \\
29 / 154(18.8) \\
21 / 154(13.6) \\
13 / 154(8.4) \\
6 / 154(3.9) \\
26 / 154(16.9)\end{array}$ & $\begin{array}{c}2(1-3) \\
12 / 64(18.8) \\
18 / 64(29) \\
36 / 64(56.3) \\
20 / 64(31.3) \\
16 / 64(25.0) \\
15 / 64(23.4) \\
15 / 64(23.4) \\
9 / 64(14.1) \\
4 / 64(6.3) \\
3 / 64(4.7) \\
14 / 64(21.9)\end{array}$ & $\begin{array}{c}2(1-3) \\
11 / 90(12.2) \\
19 / 90(21.6) \\
63 / 90(70.0) \\
35 / 90(38.9) \\
26 / 90(28.9) \\
15 / 90(16.7) \\
14 / 90(15.6) \\
12 / 90(13.3) \\
9 / 90(10) \\
3 / 90(3.3) \\
12 / 90(13.3)\end{array}$ & $\begin{array}{c}0.691 \\
0.263 \\
0.298 \\
0.079 \\
0.330 \\
0.593 \\
0.296 \\
0.218 \\
0.897 \\
0.5596 \\
0.6883 \\
-\end{array}$ \\
\hline SOFA-score (on ICU admission), $\mathrm{n}=152$ & $6(3-9)$ & $6(3-10)$ & $5(2-9)$ & 0.407 \\
\hline Apache II-score (on ICU admission), $\mathrm{n}=150$ & $18(13-26)$ & $18(14-22)$ & $19(12-28)$ & 0.576 \\
\hline $\begin{array}{l}\text { Laboratory findings on ICU admission } \\
\text { LDH }(\mathrm{U} / \mathrm{L}), \mathrm{n}=144 \\
\text { Albumin }(\mathrm{g} / \mathrm{dL}), \mathrm{n}=134 \\
\text { CRP }(\mathrm{mg} / \mathrm{dL}), \mathrm{n}=146 \\
\text { PCT }(\mathrm{ng} / \mathrm{mL}), \mathrm{n}=150 \\
\text { D-Dimer }(\mu \mathrm{g} / \mathrm{L} \text { FEU), } \mathrm{n}=125 \\
\text { Leucocytes }(\mathrm{G} / \mathrm{L}), \mathrm{n}=152 \\
\text { Lymphocytes }(\mathrm{G} / \mathrm{L}), \mathrm{n}=133 \\
\text { Il6 (pg/mL), } \mathrm{n}=133 \\
\text { 25-OH-vitamin } \mathrm{D}_{3}(\mathrm{ng} / \mathrm{mL}), \mathrm{n}=128\end{array}$ & $\begin{array}{c}448(359-599) \\
3.1(2.8-3.4) \\
12.6(6.7-20.4) \\
0.3(0.1-0.7) \\
1701(982-6333) \\
9.14(6.04-11.79) \\
0.94(0.56-1.49) \\
109(56-226) \\
15(8-26)\end{array}$ & $\begin{array}{c}448(325-568) \\
3.1(2.8-3.6) \\
13.3(8.2-21.0) \\
0.2(0.1-0.6) \\
1799(1089-6617) \\
7.93(5.85-10.76) \\
1.47(0.88-2.57) \\
115(71-183) \\
13(8-26)\end{array}$ & $\begin{array}{c}451(374-614) \\
3.1(2.7-3.4) \\
9.9(5.8-19.0) \\
0.3(0.1-0.7) \\
1535(923-5668) \\
9.86(6.30-12.78) \\
0.75(0.47-1.09) \\
109(49-268) \\
17(8-26)\end{array}$ & $\begin{array}{c}0.136 \\
0.857 \\
0.112 \\
0.803 \\
0.646 \\
\\
\mathbf{0 . 0 4 8} \\
0.887 \\
0.418\end{array}$ \\
\hline 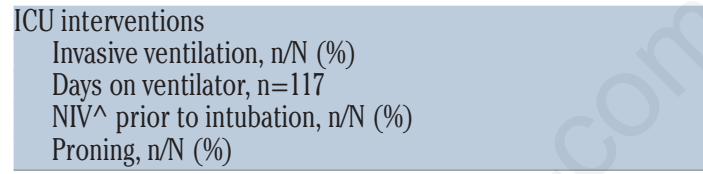 & $\begin{array}{l}117 / 154(76.0) \\
15(8-25) \\
11 / 117(9.4) \\
57 / 117(48.7)\end{array}$ & $\begin{array}{l}49 / 64(76.6) \\
16(8-35) \\
2 / 49(4.1) \\
23 / 49(46.9)\end{array}$ & $\begin{array}{l}68 / 90(75.6) \\
14(8-21) \\
9 / 68(13.2) \\
34 / 68(50.0)\end{array}$ & $\begin{array}{c}0.885 \\
0.324 \\
- \\
0.816\end{array}$ \\
\hline ECMO, n/N (\%) & $11 / 154(7.1)$ & $7 / 64(10.9)$ & $4 / 90(4.4)$ & - \\
\hline CRRT, n/N (\%) & 49/154 (31.8) & $24 / 64(37.5)$ & $25 / 90(27.8)$ & 0.222 \\
\hline $\begin{array}{l}\text { Antibiotic therapy and detected pathogens } \\
\text { Primary antibiotic therapy, n/N (\%) } \\
\text { Meropenem, n/N (\%) } \\
\text { Piperacillin/tazobactam, n/N (\%) } \\
\text { Ampicillin/sulbactam, n/N (\%) } \\
\text { Other, n/N (\%) }\end{array}$ & $\begin{array}{l}129 / 152(84.9) \\
17 / 129(13.2) \\
71 / 129(55.0) \\
37 / 129(28.7) \\
4 / 129(3.1)\end{array}$ & $\begin{array}{c}60 / 63(95.2) \\
9 / 60(15.0) \\
26 / 60(43.3) \\
22 / 60(36.7) \\
3 / 60(5.0)\end{array}$ & $\begin{array}{c}69 / 89(77.5) \\
8 / 69(11.6) \\
45 / 69(65.2) \\
15 / 69(21.7) \\
1 / 69(1.4)\end{array}$ & $\begin{array}{c}\mathbf{0 . 0 0 3} \\
0.609 \\
\mathbf{0 . 0 1 4} \\
\mathbf{0 . 0 1 3} \\
-\end{array}$ \\
\hline Initial addition of azithromycin, $\mathrm{n} / \mathrm{N}(\%)$ & $52 / 152(34.2)$ & $37 / 63(58.7)$ & $15 / 89(16.9)$ & 0.000 \\
\hline $\begin{array}{l}\text { Change of antibiotic therapy, } \mathrm{n} / \mathrm{N}(\%) \\
\text { Escalation, } \mathrm{n} / \mathrm{N}(\%) \\
\text { Addition of vancomycin or linezolid, } \mathrm{n} / \mathrm{N}(\%) \\
\text { Addition of antifungal, } \mathrm{n} / \mathrm{N}(\%)\end{array}$ & $\begin{array}{l}98 / 154(63.3) \\
79 / 98(80.6) \\
50 / 98(51.0) \\
37 / 98(37.8)\end{array}$ & $\begin{array}{l}48 / 64(75.0) \\
37 / 48(77.1) \\
23 / 48(47.9) \\
21 / 48(43.8)\end{array}$ & $\begin{array}{l}50 / 90(55.6) \\
42 / 50(84.0) \\
27 / 50(54.0) \\
16 / 50(32.0)\end{array}$ & $\begin{array}{c}\mathbf{0 . 0 1 3} \\
0.387 \\
0.547 \\
0.230\end{array}$ \\
\hline $\begin{array}{l}\text { Any meropenem use, } \mathrm{n} / \mathrm{N}(\%) \\
\text { Susceptibility testing justifying meropenem use, } \mathrm{n} / \mathrm{N}(\%)\end{array}$ & $\begin{array}{l}75 / 154(48.7) \\
15 / 75(20.0)\end{array}$ & $\begin{array}{l}33 / 64(51.6) \\
1 / 33(3.0)\end{array}$ & $\begin{array}{l}42 / 90(46.7) \\
14 / 42(33.3)\end{array}$ & $\begin{array}{c}0.624 \\
\mathbf{0 . 0 0 1}\end{array}$ \\
\hline $\begin{array}{l}\text { Blood stream infection (BSI, n/N (\%) } \\
\text { More than one BSI episode, n/N (\%) }\end{array}$ & $\begin{array}{l}35 / 118(29.7) \\
9 / 35(25.7)\end{array}$ & $\begin{array}{l}17 / 55(30.9) \\
4 / 17(23.5)\end{array}$ & $\begin{array}{l}18 / 63(28.6) \\
5 / 18(27.8)\end{array}$ & $\begin{array}{l}0.782 \\
0.892\end{array}$ \\
\hline Detection of respiratory pathogen, $\mathrm{n} / \mathrm{N}(\%)$ & $81 / 108(75.0)$ & $30 / 45(66.7)$ & $51 / 63(81.0)$ & 0.091 \\
\hline Polymicrobial respiratory infection, n/N (\%) & $49 / 108(45.4)$ & $14 / 45(31.1)$ & $35 / 63(55.6)$ & 0.012 \\
\hline Respiratory detection of $A$. fumigatus, $\mathrm{n} / \mathrm{N}(\%)$ & 23/108 (21.3) & $9 / 45(20.0)$ & $14 / 63(22.2)$ & 0.781 \\
\hline
\end{tabular}

*Due to the retrospective nature of the study, not all parameters were available for all included patients leading to differing group sizes indicated by "N" for each variable; \#Chi Square or Wilcoxon rank-

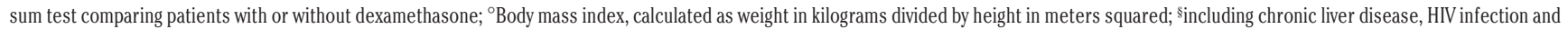
congestive heart failure; ^ non-invasive ventilation (including high-flow nasal cannula). ICU, intensive care unit; COPD, chronic obstructive pulmonary disease; SOFA, sequential organ failure assessment, APACHE, acute physiology and chronic health evaluation; ECMO, extracorporeal membrane oxygenation; CRRT, continuous renal replacement therapy. 
pathogens was present and A.fumigatus was detected in $21.3 \%$. Enterobacterales, $S$. aureus, and A. fumigatus were the most frequently detected species. Interestingly, $P$. aeruginosa and $S$. maltophilia were detected mainly in the dexamethasone group. Moreover, we noticed an increase in multidrug-resistant pathogens during the second wave of the pandemic (dexamethasone group). MRSA and ESBL-positive Enterobacterales were almost exclusively detectable in the dexamethasone group (Table 2).

To further analyze the association of dexamethasone therapy with detection of potential secondary infections, we used a multivariable logistic regression analyzing the effect of the three variables: dexamethasone, number of comorbidities, and sex, on potential infectious complications. In COVID-19 patients admitted to the ICU, only the number of comorbidities was significantly associated with BSIs and respiratory detection of $A$. fumigatus, but dexamethasone was associated with a higher rate of detectable respiratory pathogens. A significantly higher proportion of patients in the dexamethasone group showed polymicrobial detection of pathogens in the respiratory samples (Table 3 ).

\section{Discussion}

Empirical antimicrobial therapy is a common practice in COVID-19 ICU patients, but there is a paucity of data on the prevalence of secondary bacterial infections, specifically in critically ill patients [21]. Up to $40 \%$ of bacterial co-infections have been reported in this patient collective, encouraging the administration of empirical antibiotic therapy at ICU admission $[22,23]$. The present study demonstrates that over 50\% of all COVID-19 ICU develop detectable respiratory pathogens in pulmonary samples during hospital stay. During the COVID-19 pandemic, increased utilization of antimicrobials has been reported, highlighting the need for adherence to ABS principles to optimize antibiotic indication, duration, and discontinuation or de-escalation strategies $[24,25]$. Piperacillin/tazobactam was shown to be the most frequently used antibiotic in this setting [26] and long-term consequences of liberal use of broad-spectrum antibiotics must be taken into consideration. ABS strategies aim to optimize antibiotic use to improve patient management and prevent unnecessary antibiotic use, fighting the emergence of antimicrobial resistance. In line with this, in our cohort, empirical administration of antibiotic therapy and empirical use of macrolide antibiotics directly at hospital admission were reduced in the second wave of the pandemic (dexamethasone group) based on available data on low rates of community-acquired coinfections and guided by the local ABS strategy.

In critically ill COVID-19 patients, knowledge of secondary infections remains sparse. In a longitudinal analysis of respiratory specimens and blood cultures in COVID-19 patients admitted to the ICU, secondary bacterial infections were frequently detected despite empirical antimicrobial coverage and posed a major risk factor for mortality. Similar to our findings, in this cohort Enterobacterales have been reported to be the most frequently isolated respiratory pathogens [27]. Respiratory microbiological diag-

Table 2. Detected species in respiratory samples and blood cultures during hospital stay.

\begin{tabular}{|c|c|c|c|}
\hline $\begin{array}{l}\text { Detected respiratory species } \\
\text { during hospital stay }\end{array}$ & $\begin{array}{l}\text { Respiratory species } \\
\text { in total cohort } \\
(\mathbf{n = 1 8 6})\end{array}$ & $\begin{array}{l}\text { Respiratory species in } \\
\text { no-dexamethasone group } \\
(\mathrm{n}=54)\end{array}$ & $\begin{array}{l}\text { Respiratory species } \\
\text { in dexamethasone group } \\
(n=132)\end{array}$ \\
\hline Enterobacterales* & $\begin{array}{c}113(61 \%) \\
\text { (13 ESBL-positive, } \\
2 \text { Carbapenem-resistantb) }\end{array}$ & $\begin{array}{c}35(65 \%) \\
\text { (1 ESBL-positive) }\end{array}$ & $\begin{array}{c}78(59 \%) \\
(12 \text { ESBL-positive, } \\
\left.2 \text { Carbapenem-resistant }^{\circ}\right)\end{array}$ \\
\hline S. aureus & $31(16.7 \%)$ & $7(13 \%)$ & $24(18 \%)$ \\
\hline & (7 MRSA) & (1 MRSA) & (6 MRSA) \\
\hline A. fumigatus & $24(13 \%)$ & $10(19 \%)$ & $14(11 \%)$ \\
\hline P. aeruginosa & $11(6 \%)$ & $2(4 \%)$ & $9(7 \%)$ \\
\hline S. maltophilia & $5(3 \%)$ & 0 & $5(4 \%)$ \\
\hline Other ${ }^{\#}$ & $3(2 \%)$ & 0 & $3(2 \%)$ \\
\hline $\begin{array}{l}\text { Detected species in blood } \\
\text { cultures during hospital stay }\end{array}$ & $\begin{array}{l}\text { Blood stream infections } \\
\text { in total cohort } \\
(n=54)\end{array}$ & $\begin{array}{l}\text { Blood stream infections } \\
\text { in no-dexamethasone group } \\
\qquad(\mathrm{n}=24)\end{array}$ & $\begin{array}{l}\text { Blood stream infections } \\
\text { in dexamethasone group } \\
\qquad(\mathrm{n}=30)\end{array}$ \\
\hline Enterobacterales ${ }^{\S}$ & $16(30 \%)$ & $6(25 \%)$ & $10(33 \%)$ \\
\hline CoNS & $12(22 \%)$ & $8(33 \%)$ & $4(13 \%)$ \\
\hline E. faecium & $\begin{array}{l}11(20 \%) \\
\text { (8 VRE) }\end{array}$ & $\begin{array}{l}6(25 \%) \\
(4 \mathrm{VRE})\end{array}$ & $\begin{array}{l}5(17 \%) \\
(4 \mathrm{VRE})\end{array}$ \\
\hline C. albicans & $5(9 \%)$ & $3(13 \%)$ & $2(7 \%)$ \\
\hline E. feacalis & $4(7 \%)$ & 0 & $4(13 \%)$ \\
\hline S. aureus & $3(6 \%)$ & 0 & $3(10 \%)$ \\
\hline P. aeruginosa & $2(4 \%)$ & $1(4 \%)$ & $1(3 \%)$ \\
\hline S. agalacitae & $1(2 \%)$ & 0 & $1(3 \%)$ \\
\hline
\end{tabular}

*Group consists of Klebsiella spp. $(\mathrm{n}=40)$, E. coli $(\mathrm{n}=24)$, E. cloacae $(\mathrm{n}=13)$, S. marcescens $(\mathrm{n}=12)$, Proteus $\mathrm{spp} .(\mathrm{n}=10)$, Citrobacter $\mathrm{spp}$. ( $\mathrm{n}=10)$, H. alveii $(\mathrm{n}=2)$, and M. morganii $(\mathrm{n}=2) ;$; detection of OXA-48 carbapenemase; 'oroup consists of $H$. influenzae $(\mathrm{n}=2)$, A. pittii $(\mathrm{n}=1)$; \$group consists of Klebsiella spp. $(\mathrm{n}=6)$, E. coli $(\mathrm{n}=6)$, C. koseri $(\mathrm{n}=2)$, S. marcescens $(\mathrm{n}=2)$; ESBL, extended spectrum beta lactamase; MRSA, methicillin resistant Staphylococcus aureus; CoNS, coagulase-negative staphylococci; VRE, vancomycin resistant enterococci . 
nostic tests with consequent narrow-spectrum antibiotic therapy can be a valuable approach to reduce antimicrobial overuse [28]. In addition, local antimicrobial resistance patterns may vary considerably and only by repetitive longitudinal sampling strategies can an optimal antimicrobial therapy based on susceptibility testing be achieved. Therefore, we used a regular longitudinal sampling approach to closely monitor our COVID-19 patients admitted to the ICU for secondary respiratory infections. Our results indicate that more than two thirds of all COVID-19 ICU patients were in danger of developing secondary pulmonary infections during their hospital stay. This fraction was higher in the dexamethasone group. Interestingly, polymicrobial detection of respiratory pathogens was significantly more frequent in the dexamethasone group, and pathogens characteristic of treatment-related nosocomial colonization, such as $P$. aeruginosa and $S$. maltophilia, were mainly found in the dexamethasone group. Moreover, multi-resistant pathogens such as MRSA and ESBL-positive Enterobacterales were increasingly detectable in the dexamethasone group during the second wave of the pandemic. Due to a change in epidemiology between the two waves of the pandemic in Germany, patients in the dexamethasone group were significantly older in our cohort. Possibly, older age might be indicative of more preceding contacts with the healthcare system and higher rates of colonization with ESBL-positive Enterobacterales. However, increased rates of multidrug-resistant pathogens have been reported during the pandemic. During the 2003 SARS-CoV-1 outbreak, MRSA was more frequent among ICU patients following the use of broad-spectrum antibiotics [29]. In a single-center study on bacterial infections in COVID-19 ICU patients, ceftriaxone was routinely empirically administered during hospital stay prior to ICU admission, and multidrug-resistant Acinetobacter baumannii was detectable in respiratory specimens in the majority of the cohort [30]. Overuse of antimicrobials is the main driver of antibiotic resistance, which leads to unfavorable clinical outcomes [7]. During the COVID-19 pandemic, the spread of carbapenem-resistant K. pneumoniae isolates in ICU patients has been documented. This was attributed to high rates of antimicrobial use, transmissions due to the high intensity of care, the increased burden on hospitals, and the difficulties of working with full personal equipment [31-33]. In our cohort, we observed only one case of transmission of carbapenem-resistant OXA-48 carbapenemase-positive $K$. oxytoca. Therefore, we believe that nosocomial transmission was not a significant problem in our COVID-19 ICU cohort, as infection control interventions could be successfully maintained during the pandemic.

Aside from respiratory secondary bacterial infections, increased rates of nosocomial BSIs in COVID-19 ICU patients have been demonstrated [34,35]. Dexamethasone therapy had no effect on rates of nosocomial BSI in our cohort and an analysis of resistance patterns of detected pathogens in BSI did not show a significant difference in multidrug-resistant pathogens between the groups. Dexamethasone therapy had no effect on respiratory detection of A. fumigatus but was however associated with increased respiratory pathogen detection in COVID-19 patients (OR 2.10). Also, polymicrobial detection of respiratory pathogens was significantly more frequent in the dexamethasone group (OR 2.86). This may have contributed to the slightly higher mortality observed. Our results highlight the need for systematic microbiological sampling strategies in COVID-19 patients in the ICU especially in patients with dexamethasone therapy to allow directed antimicrobial therapy in cases of secondary infection. Local ABS guidelines on microbiological diagnostic, empirical treatment, and de-escalation strategies can help to optimize and limit the use of antimicrobial agents to reduce the emergence of antimicrobial resistance $[36,37]$ during the pandemic.

The present study must be interpreted with caution because of the limited cohort size. Another important limitation of the study is, that detection of respiratory pathogens in severely ill COVID19-ICU patients might in some cases represent mere colonization instead of pulmonary infection and the retrospective nature of the study does not allow to fully resolve this aspect. However, differentiation can sometimes be complicated by preexisting bilateral radiological infiltrates, elevated temperature, and the fact that dexamethasone therapy itself leads to elevation in white blood cell count. More studies are needed to evaluate the prognostic relevance of secondary infections in COVID-19 patients and the possible risk of infectious complications associated with dexamethasone therapy. Due to the retrospective nature of the study, no further follow up data after discharge from hospital and no information on final clinical outcome or development of post-COVID-19syndrome was available. However, our data increase our knowledge of respiratory pathogens in COVID-19 patients admitted to the ICU and highlight the relevance of strategies to gain insights into local epidemiology, resistance patterns, and consequences of pulmonary superinfections in COVID-19 patients.

Table 3. Association of dexamethasone therapy with infectious complications.

\begin{tabular}{|c|c|c|c|}
\hline & $\begin{array}{c}\text { Dexamethasone } \\
\text { odds ratio }(95 \% \mathrm{CI}) \\
\text { p }\end{array}$ & $\begin{array}{l}\text { Male vs female sex } \\
\text { odds ratio }(95 \% \mathrm{CI}) \\
\text { p }\end{array}$ & $\begin{array}{l}\text { N of comorbidities } \\
\text { odds ratio }(95 \% \mathrm{CI}) \\
\text { p }\end{array}$ \\
\hline Detection of respiratory pathogen & $\begin{array}{c}2.10(0.87-5.12) \\
0.100\end{array}$ & $\begin{array}{c}1.72(0.69-4.33) \\
0.248\end{array}$ & $\begin{array}{c}0.97(0.73-1.30) \\
0.840\end{array}$ \\
\hline Polymicrobial detection of respiratory pathogens & $\begin{array}{c}2.86(1.24-6.59) \\
0.013\end{array}$ & $\begin{array}{c}3.41(1.36-8.53) \\
0.009\end{array}$ & $\begin{array}{c}0.95(0.73-1.24) \\
0.714\end{array}$ \\
\hline Blood stream infection & $\begin{array}{c}0.87(0.39-1.95) \\
0.734\end{array}$ & $\begin{array}{c}1.03(0.41-2.59) \\
0.941\end{array}$ & $\begin{array}{c}1.31(1.03-1.67) \\
0.030\end{array}$ \\
\hline Pulmonary detection of $A$. fumigatus & $\begin{array}{c}1.18(0.44-3.17) \\
0.739\end{array}$ & $\begin{array}{c}1.71(0.56-5.22) \\
0.345\end{array}$ & $\begin{array}{c}1.49(1.09-2.03) \\
0.012\end{array}$ \\
\hline
\end{tabular}

Multivariable logistic regression analysis with dexamethasone, number of comorbidities and sex as covariates for the binary outcomes respiratory detection of $A$. fumigatus, respiratory infection, polymicrobial respiratory infection and blood stream infection. 


\section{Conclusions}

Secondary infections are present in a relevant proportion of critically ill COVID-19 patients, and antibiotic therapy must be adjusted for susceptibility testing and local epidemiology. Infectious complications are associated with worse outcomes and the use of dexamethasone in this patient cohort additionally poses a potential risk especially for pulmonary secondary infections. As detection of respiratory pathogens in severely ill COVID-19-ICU patients might in some cases represent mere colonization, profound clinical evaluation is necessary to avoid antibiotic overuse. Respiratory pathogens in severely ill COVID-19-ICU patients with dexamethasone therapy should be microbiologically monitored to allow directed antimicrobial therapy in cases of definite secondary infection.

\section{Abbreviations}

ABS: antibiotic stewardship;

APACHE: acute physiology and chronic health evaluation;

ARDS: acute respiratory distress syndrome;

BAL: bronchoalveolar lavage fluid;

BC: blood culture;

BSI: blood stream infection;

CI: confidence interval;

CoNS: coagulase-negative staphylococci;

COVID-19: coronavirus disease 2019;

ICU: intensive care units;

SARS-CoV-2: severe acute respiratory syndrome coronavirus 2; SOFA: sequential organ failure assessment.

\section{References}

1. Richardson S, Hirsch JS, Narasimhan M, Crawford JM, McGinn T, Davidson KW, et al. Presenting characteristics, comorbidities, and outcomes among 5700 patients hospitalized with COVID-19 in the New York City area. JAMA 2020;323:2052-9.

2. Guan WJ, Ni ZY, Hu Y, Liang WH, Ou CQ, He JX, et al. Clinical characteristics of coronavirus disease 2019 in China. N Engl J Med 2020;382:1708-20.

3. Vaughn VM, Gandhi T, Petty LA, Patel PK, Prescott HC, Malani AN, et al. Empiric antibacterial therapy and community-onset bacterial co-infection in patients hospitalized with COVID-19: A multi-hospital cohort study. Clin Infect Dis 2021;72:e533-41.

4. Lansbury L, Lim B, Baskaran V, Lim WS. Co-infections in people with COVID-19: a systematic review and meta-analysis. J Infect 2020;81:266-75.

5. Zhou F, Yu T, Du R, Fan G, Liu Y, Liu Z, et al. Clinical course and risk factors for mortality of adult inpatients with COVID19 in Wuhan, China: a retrospective cohort study. Lancet 2020;395:1054-62.

6. De Waele JJ, Derde L, Bassetti M. Antimicrobial stewardship in ICUs during the COVID-19 pandemic: back to the 90s? Intensive Care Med 2021;47:104-6.

7. Sticchi C, Alberti M, Artioli S, Assensi M, Baldelli I, Battistini A, et al. Regional point prevalence study of healthcare-associated infections and antimicrobial use in acute care hospitals in Liguria, Italy. J Hosp Infect 2018;99:8-16.

8. Chang CY, Chan KG. Underestimation of co-infections in
COVID-19 due to non-discriminatory use of antibiotics. J Infect 2020;81:e29-e30.

9. Sterne JAC, Murthy S, Diaz JV, Slutsky AS, Villar J, Angus DC, et al. Association between administration of systemic corticosteroids and mortality among critically ill patients with COVID-19: A meta-analysis. JAMA 2020;324:1330-41.

10. The RECOVERY Collaborative Group. Dexamethasone in hospitalized patients with Covid-19 - Preliminary report. N Engl J Med 2020:NEJMoa2021436.

11. Villar J, Ferrando C, Martínez D, Ambrós A, Muñoz T, Soler JA, et al. Dexamethasone treatment for the acute respiratory distress syndrome: a multicentre, randomised controlled trial. Lancet Respir Med 2020;8:267-76.

12. Dagens A, Sigfrid L, Cai E, Lipworth S, Cheng V, Harris E, et al. Scope, quality, and inclusivity of clinical guidelines produced early in the covid-19 pandemic: rapid review. BMJ 2020;369:m1936.

13. Rodrigo C, Leonardi-Bee J, Nguyen-Van-Tam J, Lim WS. Corticosteroids as adjunctive therapy in the treatment of influenza. Cochrane Database Syst Rev 2016;3:CD010406.

14. Arabi YM, Mandourah Y, Al-Hameed F, Sindi AA, Almekhlafi GA, Hussein MA, et al. Corticosteroid therapy for critically ill patients with Middle East respiratory syndrome. Am J Respir Crit Care Med 2018;197:757-67.

15. Lee N, Allen Chan KC, Hui DS, Ng EK, Wu A, Chiu RW, et al. Effects of early corticosteroid treatment on plasma SARSassociated Coronavirus RNA concentrations in adult patients. J Clin Virol 2004;31:304-9.

16. Lee N, Chan PK, Hui DS, Rainer TH, Wong E, Choi KW, et al. Viral loads and duration of viral shedding in adult patients hospitalized with influenza. J Infect Dis 2009;200:492-500.

17. Rothe K, Feihl S, Schneider J, Wallnöfer F, Wurst M, Lukas M, et al. Rates of bacterial co-infections and antimicrobial use in COVID-19 patients: a retrospective cohort study in light of antibiotic stewardship. Eur J Clin Microbiol Infect Dis 2020;40:859-69.

18. Chastre J, Fagon JY. Ventilator-associated pneumonia. Am J Respir Crit Care Med 2002;165:867-903.

19. Kaeuffer C, Le Hyaric C, Fabacher T, Mootien J, Dervieux B, Ruch Y, et al. Clinical characteristics and risk factors associated with severe COVID-19: prospective analysis of 1,045 hospitalised cases in North-Eastern France, March 2020. Euro Surveill 2020;25:2000895.

20. CDC COVID-19 Response Team. Severe Outcomes among patients with coronavirus disease 2019 (COVID-19) - United States, February 12-March 16, 2020. MMWR Morb Mortal Wkly Rep 2020;69:343-6.

21. Langford BJ, So M, Raybardhan S, Leung V, Westwood D, MacFadden DR, et al. Bacterial co-infection and secondary infection in patients with COVID-19: a living rapid review and meta-analysis. Clin Microbiol Infect 2020;26:1622-9.

22. Contou D, Claudinon A, Pajot O, Micaëlo M, Longuet Flandre $\mathrm{P}$, Dubert $\mathrm{M}$, et al. Bacterial and viral co-infections in patients with severe SARS-CoV-2 pneumonia admitted to a French ICU. Ann Intensive Care 2020;10:119.

23. Bassetti M, Kollef MH, Timsit JF. Bacterial and fungal superinfections in critically ill patients with COVID-19. Intensive Care Med 2020;46:2071-4.

24. Furukawa D, Graber CJ. Antimicrobial stewardship in a pandemic: picking up the pieces. Clin Infect Dis 2021;72:e542-4.

25. Gonzalez-Zorn B. Antibiotic use in the COVID-19 crisis in Spain. Clin Microbiol Infect 2021;27:646-7.

26. Beović B, Doušak M, Ferreira-Coimbra J, Nadrah K, Rubulotta F, Belliato M, et al. Antibiotic use in patients with 
COVID-19: a 'snapshot' Infectious Diseases International Research Initiative (ID-IRI) survey. J Antimicrob Chemother 2020;75:3386-90.

27. Buehler PK, Zinkernagel AS, Hofmaenner DA, García PDW, Acevedo CT, Gómez-Mejia A, et al. Bacterial pulmonary superinfections are associated with unfavourable outcomes in critically ill COVID-19 patients. medRxiv 2020:2020.09.10.20191882.

28. Verroken A, Scohy A, Gérard L, Wittebole X, Collienne C, Laterre PF. Co-infections in COVID-19 critically ill and antibiotic management: a prospective cohort analysis. Crit Care 2020;24:410.

29. Yap FH, Gomersall CD, Fung KS, Ho PL, Ho OM, Lam PK, et al. Increase in methicillin-resistant Staphylococcus aureus acquisition rate and change in pathogen pattern associated with an outbreak of severe acute respiratory syndrome. Clin Infect Dis 2004;39:511-6.

30. Sharifipour E, Shams S, Esmkhani M, Khodadadi J, FotouhiArdakani R, Koohpaei A, et al. Evaluation of bacterial coinfections of the respiratory tract in COVID-19 patients admitted to ICU. BMC Infect Dis 2020;20:646.

31. Tiri B, Sensi E, Marsiliani V, Cantarini M, Priante G, Vernelli C, et al. Antimicrobial stewardship program, COVID-19, and infection control: Spread of carbapenem-resistant klebsiella pneumoniae colonization in ICU COVID-19 patients. What did not work? J Clin Med 2020;9:2744.

32. Arcari G, Raponi G, Sacco F, Bibbolino G, Di Lella FM,
Alessandri F, et al. Klebsiella pneumoniae infections in COVID-19 patients: a 2-month retrospective analysis in an Italian hospital. Int J Antimicrob Agents 2021;57:106245.

33. Arteaga-Livias K, Pinzas-Acosta K, Perez-Abad L, PanduroCorrea V, Rabaan AA, Pecho-Silva S, et al. A multidrug-resistant Klebsiella pneumoniae outbreak in a Peruvian hospital: Another threat from the COVID-19 pandemic. Infect Control Hosp Epidemiol 2021;1-2. Online ahead of print.

34. Sturdy A, Basarab M, Cotter M, Hager K, Shakespeare D, Shah N, et al. Severe COVID-19 and healthcare-associated infections on the ICU: time to remember the basics? J Hosp Infect 2020;105:593-5.

35. Buetti N, Ruckly S, de Montmollin E, Reignier J, Terzi N, Cohen Y, et al. COVID-19 increased the risk of ICU-acquired bloodstream infections: a case-cohort study from the multicentric OUTCOMEREA network. Intensive Care Med 2021;47:180-7.

36. Dellit TH, Owens RC, McGowan JE Jr., Gerding DN, Weinstein RA, Burke JP, et al. Infectious Diseases Society of America and the Society for Healthcare Epidemiology of America guidelines for developing an institutional program to enhance antimicrobial stewardship. Clin Infect Dis 2007;44:159-77.

37. Ewig S, Höffken G, Kern WV, Rohde G, Flick H, Krause R, et al. [Management of Adult Community-acquired Pneumonia and Prevention - Update 2016].[Article in German]. Pneumologie 2016;70:151-200.

Received for publication: 6 July 2021. Accepted for publication: 1 October 2021.

This work is licensed under a Creative Commons Attribution-NonCommercial 4.0 International License (CC BY-NC 4.0).

(C) Copyright: the Author(s), 2021

Licensee PAGEPress, Italy

Multidisciplinary Respiratory Medicine 2021; 16:793

doi:10.4081/mrm.2021.793 